\title{
A Study to Determine Prevalence of Left Ventricular Hypertrophy And it's Correlation with Vitamin D Levels in Patients of Chronic Kidney Disease on Hemodialysis.
}

\author{
Bhatnagar $\mathrm{M}^{*}$, Bhagi $\mathrm{R}^{* *}$, Jha Sk*** \\ Pg Dept. Of Medicine, Subharti Medical College, Meerut
}

\section{Introduction}

Chronic kidney disease (CKD) is an emerging public health problem andis the leading risk factor for cardiovascular disease (CVD), a great threat to health and an economic burden ${ }^{1}$, particularly in developing countries, because therapy is expensive and life-long. In India $\sim 90 \%$ patients cannot afford the $\operatorname{cost}^{2}$. In India, it has been recently estimated that the age-adjusted incidence rate of ESRD to be 229 per million population ${ }^{3}$, and $>100,000$ new patients enter renal replacement programs annually ${ }^{4}$. The prevalence of CVD was observed to be $17.2 \%$ with $\sim 6 \%$ have CKD stage 3 or worse ${ }^{5}$.

Vitamin D deficiency is highly prevalent in CKD and has been proposed to be a non-traditional risk factor, but its relationship with cardiac structure is unknown.

Traditionally, vitamin D has been associated primarily with bone health, and it is well understood that vitamin D deficiency leads to rickets in children and osteomalacia and osteoporosis in adults ${ }^{6}$. However, it is now known that adequate vitamin $\mathrm{D}$ status is important for optimal function of many organs and tissues throughout the body, including the cardiovascular (CV) system ${ }^{7}$. Vitamin D receptors (VDRs) are present on a large variety of cell types, including myocytes, cardiomyocytes, pancreatic beta-cells, vascular endothelial cells, neurons, immune cells, and osteoblasts. ${ }^{8}$

Vitamin D deficiency activates the renin-angiotensin-aldosterone system and can predispose to hypertension and left ventricular hypertrophy. Additionally, vitamin D deficiency causes an increase in parathyroid hormone, which increases insulin resistance and is associated with diabetes, hypertension, inflammation, and increased cardiovascular risk. Epidemiologic studies have associated low 25-hydroxyvitamin D levels with coronary risk factors and adverse cardiovascular outcomes. ${ }^{8}$ Observational studies in patients with CKD report associations between vitamin D deficiency and increased risk of cardiovascular events and between therapy with calcitriol or related analogs and reduced events. ${ }^{9,10,11}$ Experimental models suggest that intermediate end points for these observations include a reduction of left ventricular hypertrophy (LVH), improved left ventricular diastolic function, and reduced episodes of heart failure. ${ }^{12,13}$

Given this background, this study was conducted to determine the prevalence of $\mathrm{LVH}$ and its correlation with vitamin D levels in patients with ESRD on hemodialysis.

\section{Aims}

To study the prevalence of left ventricular hypertrophy (LVH) in patients with end stage renal disease (ESRD) on hemodialysis and the correlation between left ventricular size and serum Vitamin D levels in patient with end stage renal disease on hemodialysis.

\section{Method}

This study was carried out at an affiliated hospital of Subharti Medical College, Meerut in the Post Graduate Department of Medicine. 100 cases of end stage renal disease were selected and presence of left ventricular hypertrophy was noted in these. Size of let ventricle was compared with levels of serum Vitamin D in the same group of subjects.

Patients included in the study were those of age > 18 years, with ESRD - defined as GFR, where GFR was calculated using the abbreviated Modification of Diet in Renal Disease Study Equation (MDRDS ${ }^{14}$ :GFR $\left(\mathrm{ml} / \mathrm{min} / 1.73 \mathrm{~m}^{2}\right.$ of body surface area) $=186 \mathrm{x}$ (serum creatinine in $\left.\mathrm{mg} / \mathrm{dl}\right)-1.154 \times$ (age in years) $-0.203 \times 0.742$ for female subjects.It was categorized based on NKF Kidney Disease Outcomes Quality Initiative guidelines. (K/DOQI guidelines, 2003) : Stage $1-$ GFR $\geq 90 \mathrm{ml} / \mathrm{min} / 1.73 \mathrm{~m}^{2}$, Stage $2-$ GFR $60-89 \mathrm{ml} / \mathrm{min} / 1.73 \mathrm{~m}^{2}$, Stage 3 - GFR 30 - $59 \mathrm{ml} / \mathrm{min} / 1.73 \mathrm{~m}^{2}$, Stage 4 - GFR $15-29 \mathrm{ml} / \mathrm{min} / 1.73 \mathrm{~m}^{2}$, Stage 5 - GFR $<15 \mathrm{ml} / \mathrm{min} / 1.73 \mathrm{~m}^{2}$ (or dialysis).

The following patients were excluded; those withovert malignancy, chronic liver disease, structural heart disease, congenital heart disease, congestive heart failure, myocardial infarction, chronic obstructive 
pulmonary disease, alcohol intake, patients undergoing any surgery or transplant, patients on vitamin $d$ supplementation, patients undergoing more than one dialysis, patients on erythropoietin.

Before inclusion all patients were introduced to the study and an informed consent will be taken.

Vitamin D was measured in all cases and echocardiogram was done and all the parameters was examined. Vitamin D deficiency was grouped as mild ,moderate and severe according to level $<5 \mathrm{ng} / \mathrm{mL}, 5-15 \mathrm{ng} / \mathrm{mL}, 15$ $30 \mathrm{ng} / \mathrm{mL}$. $^{15}$

Left Ventricular Mass index (LVMI) was calculated by Devereux's(Penn) formula. [1.04\{(IVST+LVID+PWT)3_LVID3 $\}-14]$ g, where LVID is the internal dimension, PWT is posterior wall thickness, IVST is interventricular septal thickness, 1.04=specific gravity of the myocardium, and 0.8 is the correction factor. All measurements are made at end-diastole (at onset of the $\mathrm{R}$ wave) in centimeters. Left ventricular mass index is defined as a left ventricular mass divided by body surface area(BSA). Body surface area is calculated using Du Bios formula: BSA $=(\mathrm{W}-60) \mathrm{X} 0.01+\mathrm{H}$, where BSA is the body surface area in $\mathrm{m} 2$, W is the weight in kilograms and $\mathrm{H}$ is height in meters. Referance range of LVMI was kept normal in male was $49-115(\mathrm{~g} / \mathrm{m} 2)$ and in female $43-95(\mathrm{~g} / \mathrm{m} 2)$. According to abnormal LVMI they are grouped in mild $(116$ - 131)(96-108),moderate(132-148)(109-121) and severe $(\geq 149)(\geq 122)(\mathrm{g} / \mathrm{m} 2)$ respectively in male and female. ${ }^{16}$ Statistical analysis of data was performed using SPSS V.12.0. (WINDOWS). All data obtained was summarized and expressed as mean +/- SD or as percentages as required.. Multivariate analysis was also be performed. Statistical significance was accepted as $\mathrm{P}<0.05$.

\section{Results}

\section{A 100 cases of ESRD were selected and matched for age and sex.}

The age of the cases ranged from a minimum of 19 years to a maximum of 80 years, with the mean age being 58.45 years.There were $75(75 \%)$ males and $25(25 \%)$ females in the study. The mean age of males was 58.24 and females was 59.08. Blood pressure ranged from a minimum of 104/60 - to a maximum of $-210 / 168$ with the mean SBP being - 162.12 and mean DBP being -101.24. The average blood pressure in males $-161 / 100$ and in females $-164 / 105$. Average age of females was higher than males in the hypertensive group while it was lower in the normotensive group. The maximum $\mathrm{S}$. creatinine in the study was $-13.2 \mathrm{mg} / \mathrm{dL}$ while the minimum was $-1.9 \mathrm{mg} / \mathrm{dL}$. The average s. creatinine levels in the study were $-5.17 \mathrm{mg} / \mathrm{dL}$ with an average GFR of 13.99 . The S. creatinine and GFR levels were comparable in male and female participants with mean S. creatinine in males being 5.24 and females being $4.96 \mathrm{mg} / \mathrm{dL}$. Out of 100 participants 34 were non diabetic while the rest were diabetic. Significant correlation was found only between s. vitamin D levels and creatinine levels $(\mathrm{p}=$ $0.041, \mathrm{CI}=-0.2047$ to -0.004195$)$. The prevalence of LVH in ESRD patients is $73 \%$. In males the prevalence is about $69.33 \%$ while in females it is about $84 \%$. In the age group of $18-35,35-65$ and $>65$ the incidence of LVH is $40 \%, 68.75 \%, 77.15 \%$ respectively. In hypertensive group it is $75.29 \%$ while in the normotensive group it is about $60 \%$. LVH in stage $\mathrm{V}$ of CKD is about $65.5 \%$. LVH prevalence was found to be $57.14 \%, 79.16 \%$, and $75.55 \%$ respectively in mild, moderate and sever anemia. $71.21 \%$ of diabetics were found to have $\mathrm{LVH}$ while $76.47 \%$ were non diabetics.

Table 1:-showing correlation of serum vitamin d level with various factors

\begin{tabular}{|c|c|c|c|c|c|}
\hline \multirow{2}{*}{\multicolumn{2}{|c|}{ variables }} & \multicolumn{3}{|c|}{ Serum vitamin D levels (ng/ml) } & \multirow[t]{2}{*}{$\mathrm{P}$ value $\mathrm{p}$} \\
\hline & & $<5$ & $5-15$ & $15-30$ & \\
\hline \multirow[t]{2}{*}{$\operatorname{sex}$} & males & 15 & 47 & 13 & 0.944 \\
\hline & females & 4 & 19 & 2 & \\
\hline \multirow[t]{3}{*}{ age } & $18-35$ & 2 & 3 & 0 & 0.220 \\
\hline & $35-65$ & 12 & 40 & 10 & \\
\hline & $>65$ & 5 & 23 & 5 & \\
\hline \multirow[t]{3}{*}{ s. creatinine } & $<5$ & 8 & 43 & 9 & 0.041 \\
\hline & $5-10$ & 8 & 20 & 6 & \\
\hline & $10-15$ & 3 & 3 & 0 & \\
\hline \multirow[t]{3}{*}{ Hemoglobin } & $\begin{array}{l}\text { mild }(11-11.9, \\
11-12.9)\end{array}$ & 1 & 4 & 2 & 0.934 \\
\hline & $\begin{array}{l}\text { moderate } \\
10.9)\end{array}$ & 8 & 34 & 5 & \\
\hline & severe $(<8)$ & 10 & 28 & 8 & \\
\hline
\end{tabular}


Significant correlation was found only between s. vitamin D levels and creatinine levels $(p=0.041, C I=-0.2047$ to -0.004195$)$

Figure 1 and 2 : Serum vitamin D levels with Serum creatinine

\section{S. vitamin D levels with S. creatinine}

50

40

30

20

10

0

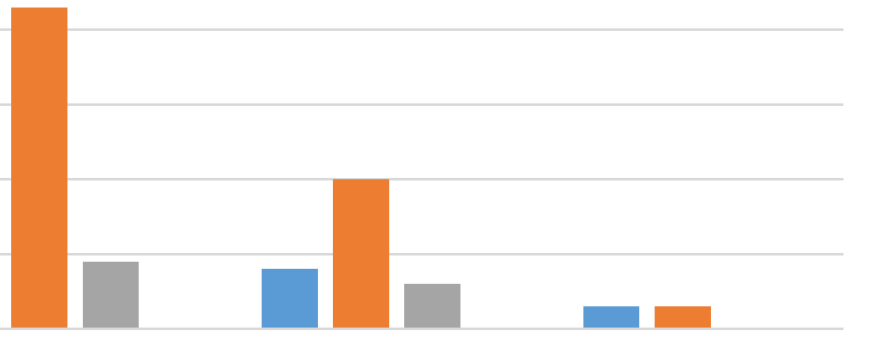

$<5$

$5-10$

10-15

$\square<5 \quad$ - 5-15 $\quad 15-30$

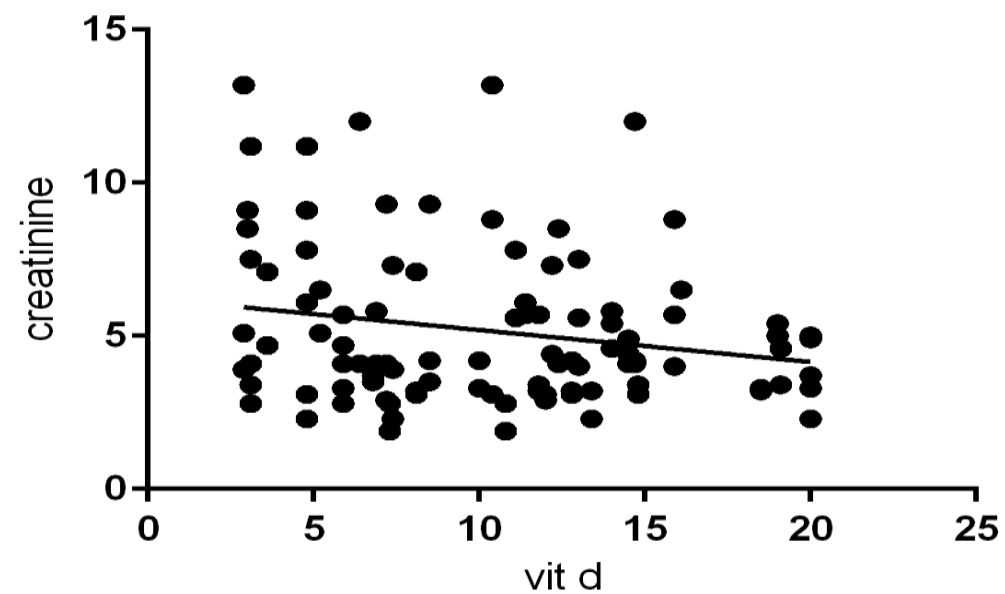

Table 2: LVMI correlation with various factors

\begin{tabular}{|c|c|c|c|c|c|c|}
\hline \multirow{2}{*}{\multicolumn{2}{|c|}{ Factors Affecting Lvmi }} & \multicolumn{5}{|c|}{ Lvmi } \\
\hline & & \multirow{2}{*}{$\begin{array}{l}\mathrm{N} \\
5\end{array}$} & \multirow{2}{*}{$\begin{array}{l}\text { Normal } \\
3\end{array}$} & \multirow{2}{*}{$\begin{array}{l}\text { Mild } \\
2\end{array}$} & \multirow{2}{*}{$\begin{array}{l}\text { Moderate } \\
0\end{array}$} & \multirow{2}{*}{$\begin{array}{l}\text { Severe } \\
0\end{array}$} \\
\hline Age & $18-35$ & & & & & \\
\hline & $35-65$ & 64 & 20 & 14 & 15 & 15 \\
\hline & $>65$ & 31 & 4 & 8 & 7 & 12 \\
\hline \multirow[t]{2}{*}{ Sex } & Male & 75 & 23 & 18 & 18 & 16 \\
\hline & Female & 25 & 4 & 6 & 4 & 11 \\
\hline \multirow[t]{2}{*}{ Blood Pressure } & Hypertensive & 85 & 21 & 21 & 20 & 23 \\
\hline & Normotensive & 15 & 6 & 3 & 2 & 4 \\
\hline \multirow[t]{2}{*}{ S. Creatinine } & $<15$ & 58 & 20 & 11 & 11 & 16 \\
\hline & $>15$ & 42 & 7 & 13 & 11 & 11 \\
\hline \multirow[t]{3}{*}{ Anemia } & $\begin{array}{l}\text { Mild (11-11.9, } 11- \\
12.9)\end{array}$ & 7 & 3 & 3 & 1 & 0 \\
\hline & Moderate (8-10.9) & 48 & 10 & 8 & 14 & 16 \\
\hline & Severe $(<8)$ & 45 & 14 & 13 & 7 & 11 \\
\hline \multirow[t]{2}{*}{ Diabetes } & Yes & 66 & 19 & 19 & 11 & 17 \\
\hline & No & 34 & 8 & 5 & 11 & 10 \\
\hline \multirow[t]{3}{*}{$\begin{array}{ll}\text { Vitamin } & \text { D } \\
\text { Deficiency } & \\
\end{array}$} & $<5$ & 19 & 4 & 6 & 3 & 6 \\
\hline & $5-15$ & 66 & 17 & 13 & 17 & 19 \\
\hline & $16-30$ & 15 & 6 & 5 & 2 & 2 \\
\hline
\end{tabular}


Table 3: shows Pearson correlation between different parameters affecting LVMI and Vitamin D status.

\begin{tabular}{|c|c|c|c|c|c|c|c|}
\hline \multicolumn{8}{|c|}{ Correlations } \\
\hline & & AGE & SBP & $\mathrm{HB}$ & EGFR & LVMI & $\begin{array}{l}\text { S. VIT D } \\
\text { LEVELS }\end{array}$ \\
\hline \multirow[t]{3}{*}{ AGE } & Pearson Correlation & 1 & -.024 & -.193 & 195 & $.244^{*}$ & .124 \\
\hline & Sig. (2-Tailed) & & .811 & .054 & .051 & .014 & .220 \\
\hline & $\mathrm{N}$ & 100 & 100 & 100 & 100 & 100 & 100 \\
\hline \multirow[t]{3}{*}{ SBP } & Pearson Correlation & -.024 & 1 & -.096 & $.200^{*}$ & .254 & $-.237^{*}$ \\
\hline & Sig. (2-Tailed) & .811 & & .344 & .046 & .019 & .018 \\
\hline & $\mathrm{N}$ & 100 & 100 & 100 & 100 & 100 & 100 \\
\hline \multirow[t]{3}{*}{ HB } & Pearson Correlation & -.193 & -.096 & 1 & .140 & .004 & .008 \\
\hline & Sig. (2-Tailed) & .054 & .344 & & .010 & .966 & .934 \\
\hline & $\mathrm{N}$ & 100 & 100 & 100 & 100 & 100 & 100 \\
\hline \multirow[t]{3}{*}{ EGFR } & Pearson Correlation & .195 & $.200^{*}$ & .140 & 1 & -.327 & .357 \\
\hline & Sig. (2-Tailed) & .051 & .046 & .010 & & .021 & .011 \\
\hline & $\mathrm{N}$ & 100 & 100 & 100 & 100 & 100 & 100 \\
\hline \multirow[t]{3}{*}{ LVMI } & Pearson Correlation & $.244^{*}$ & .254 & .004 & -.327 & 1 & -.054 \\
\hline & Sig. (2-Tailed) & .014 & .019 & .966 & .021 & & .591 \\
\hline & $\mathrm{N}$ & 100 & 100 & 100 & 100 & 100 & 100 \\
\hline \multirow{3}{*}{$\begin{array}{l}\text { S. VIT D } \\
\text { LEVELS }\end{array}$} & Pearson Correlation & .124 & $-.237^{*}$ & .008 & .357 & -.054 & 1 \\
\hline & Sig. (2-Tailed) & .220 & .018 & .934 & .011 & .591 & \\
\hline & $\mathrm{N}$ & 100 & 100 & 100 & 100 & 100 & 100 \\
\hline
\end{tabular}

- There is significant correlation between eGFR and LVMI related inversely.

- There is no significant correlation between Vitamin D level and LVMi related inversely.

- There is significant correlation between eGFR and vitamin D level.

- No significant correlation between haemoglobin level and LVMI.

\section{Conclusion}

The prevalence of LVH in ESRD was found to be 73\%. After adjustment for age, sex, hypertension, creatinine levels, anemia there was no significant association found between serum vitamin D levels and left ventricular hypertrophy.

\section{Discussion}

LVH is a common independent risk factor for cardiac death in CKD and end-stage kidney disease (ESKD) patients. The prevalence and severity of LVH increase in parallel with the severity of CKD. LVH reduces coronary reserve and induces cardiac ischemia, which may in turn promote myocardial infarction and lethal arrhythmia. ${ }^{17}$

The links among vitamin D deficiency, vitamin D therapy, and chronic disease are of considerable clinical and research interest. Although alterations in vitamin D metabolism have been associated with CVD and experimental data suggest that the vitamin D pathway is involved in modifying cardiac structure and function, corresponding clinical trial evidence is limited. ${ }^{18}$ In my study, statistically significant correlation could not be found between serum vitamin d levels and left ventricular hypertrophy.

Previous trials where a statistically significant correlation between vitamin D and left ventricular hypertrophy is seen and vitamin D has been found to be an independent predictor of vitamin D have been published. However most of these studies have either not been conducted in end stage renal disease or have failed to demonstrate a correlation between vitamin D and left ventricular hypertrophy in the same. Various studies like the OPERA ${ }^{19}$ and the PRIMO trial ${ }^{20}$, conducted to study the effect of oral activated vitamin D supplementation on left ventricular mass in chronic kidney disease patients have also failed to show any promising result.

Patange AR, Valentini RP et al., ${ }^{21}$ published a study in 2013 exploring the relationship between various parameters of calcium-phosphorus metabolism including 25-hydroxy vitamin D and cardiovascular structure and function in pediatric patients with CKD. This cross-sectional study was conducted using a cohort of 34 children with CKD who had no history of underlying congenital or structural cardiac disease. 2D echocardiography was used to measure the left ventricular mass index (LVMI), E/A ratio, $E^{\prime}, E / E^{\prime}$ ratio, and myocardial performance index (MPI). The augmentation index (AI), derived via radial artery tonometry, was used as an indirect measure of central aortic stiffness. Serum biochemical markers of calcium-phosphorus metabolism were simultaneously measured. Univariate analysis showed that LVMI correlated with 25-hydroxy vitamin D, systolic blood pressure (SBP), and AI. Serum-intact parathyroid hormone (PTH) levels correlated 
with the $\mathrm{E} / \mathrm{E}^{\prime}$ ratioand $E^{\prime}$. Multiple regression analysis showed that 25 -hydroxy vitamin D and SBP were independent predictors of increased LVMI and that PTH was an independent predictor of diastolic dysfunction. In our study, 100 subjects were studied and analyzed which revealed statistically significant correlation between LVMI and systolic blood pressure. However, it failed to demonstrate any significant correlation between 25hydroxy vitamin D and LVMI.

Another study was conducted by Mukhopadyay P et al., ${ }^{22}$ to evaluate the effect of vitamin D deficiency on cardiac structure and functions in 150 predialysis diabetic and non-diabetic CKD patients. About 96(64\%) were diabetic and rest of 54(36\%) were non diabetic. Diabetic CKD patients are more severely deficient of vitamin D than non-diabetic CKD (38\% vs $8 \%$ ). Higher stages of CKD showed severe grade of Vit D deficiency. Among all CKD patients with severe vitamin D deficiency $10 \%$ had moderately abnormal LVMI and $34 \%$ had severely abnormal LVMI and among moderate vitamin D deficient patients $24 \%$ had moderately abnormal LVMI and 14\% had severely abnormal LVMI. This correlation is extremely significant. There is significant correlation between lowVitamin D level and LVMI related inversely. In my thesis, 100 patients were studied about $66 \%$ were diabetic while the rest $34 \%$ were non diabetic. There was no significant difference in serum vitamin D levels among diabetics and non diabetics. Higher stages of CKD showed severe grading of vitamin D deficiency. Among all CKD patients with severe vitamin D deficiency $21 \%$ had moderately abnormal LVMI and 26\% had severely abnormal LVMI and among mild vitamin D deficient patients $25 \%$ had moderately abnormal LVMI and 28\% had severely abnormal LVMI. Hence the correlation was not significant. Therefore no correlation was found between vitamin D levels and LVMI.

Tove F, Ivy $\mathrm{S}$ et al., ${ }^{23}$ published a study in 2012 examining associations of circulating vitamin $\mathrm{D}$ concentrations and left ventricular (LV) geometry and function by echocardiography at baseline and after 5 years in a community-based study which included 870 patients of which $52 \%$ were women without prior myocardial infarctions, heart failure, or prevalent valvular disease. They concluded that higher circulating vitamin D concentrations were found to be associated cross-sectionally with better LV systolic function and smaller LVESD at baseline. However they could not find a causal relationship or show any statistically significant change in LVMI in the same which is in accordance with the results of this study.

Another study of 648 elderly individuals from the population-based Hoorn cohort conducted by Pilz S, Henry RMA et al., where serum levels of $25-\mathrm{OH} \mathrm{D}$ were reported as not being significantly associated with measures of LV geometry or function. ${ }^{24} \mathrm{An} 8$-year follow-up was recently published on 256 of the subjects, and the results were still mainly negative for heart structure and function. ${ }^{25}$ This is also in accordance with the findings of my thesis.

Wang AYM, Lam CWK et al., ${ }^{26}$ studied serum 25(OH)D concentrations in 230 prevalent peritoneal dialysis patients and then followed these patients prospectively for $3 \mathrm{y}$ or until death. Serum 25(OH)D was deficient or insufficient (ie, $<75 \mathrm{nmol} / \mathrm{L}$ ) in $87 \%$ of the patients. Adjusting for clinical and demographic factors, every 1-unit increase in log-transformed serum $25(\mathrm{OH}) \mathrm{D}$ was associated with a $44 \%$ reduction in the hazard of fatal or nonfatal cardiovascular events. However, the association was gradually lost when additional adjustment was made in a stepwise fashion for residual glomerular filtration rate and echocardiographic measures. A lower serum 25(OH)D concentration was associated with an increased risk of cardiovascular events in chronic peritoneal dialysis patients. Furthermore, serum $25(\mathrm{OH}) \mathrm{D}$ status appeared to show a differential influence on the cardiovascular outcomes of peritoneal dialysis patients depending on the degree of left ventricular hypertrophy and systolic dysfunction. However no correlation was found between serum vitamin D levels and left ventricular hypertrophy itself. In our study $88 \%$ patients were found to be vitamin D deficient and no correlation could be demonstrated between degree of LVH and serum vitamin D levels.

The difference in my study as compared to the previous trials could be because of the following limitations. The study has not taken into account the effect of proteinuria, serum calcium levels and parathyroid levels on left ventricular mass. Also the no of hemodialysis done and the supplementation of vitamin D analogues, parathormone analogues, anti hypertensive and anti diabetic medications have not been taken into consideration. Also vitamin D has been shown in previous trials such as those conducted by Tove F, Ivy s et al in 2012 to affect LV systolic function which has not been studied in this study.

\section{References}

[1]. Nitta, K., Iimuro, S., Imai, E. et al. Risk factors for increased left ventricular hypertrophy in patients with chronic kidney disease. Clin Exp Nephrol. 2013;17:730.

Dash SC, Agarwal SK. Incidence of chronic kidney disease in India. Nephrol. Dial. Transplant. 2006;21(1):232-233.

[3]. Modi GK, Jha V: The incidence of end-stage renal disease in India: a population-based study. Kidney Int. 2006;70(12):2131-3.

[4]. Kher V: End-stage renal disease in developing countries. Kidney Int. 2002, 62 (1): 350-62.

[5]. Singh AK, Farag YMK, Mittal BV, Subramanian KK et al. Epidemiology and risk factors of chronic kidney disease in India results from the SEEK (Screening and Early Evaluation of Kidney Disease) study. BMC Nephro.2013;14:114.

[6]. Zittermann A.; Vitamin D and disease prevention with special reference to cardiovascular disease. Prog Biophys Mol Biol. 92 2006:39-48

[7]. Holick M.F.; Vitamin D deficiency. N Engl J Med. 357 2007:266-281. 
[8]. Lee JH, Keefe JH et al. An Important, Common, and Easily Treatable Cardiovascular Risk Factor? J Am Coll Cardiol. 2008;52(24):1949-1956

[9]. Drechsler C, Pilz S, Obermayer-Pietsch B, et al. Vitamin D deficiency is associated with sudden cardiac death, combined cardiovascular events, and mortality in haemodialysis patients. Eur Heart J. 2010;31(18):2253-2261

[10]. Kalantar-Zadeh K, Kuwae N, Regidor DL, et al. Survival predictability of time-varying indicators of bone disease in maintenance hemodialysis patients. Kidney Int. 2006;70(4):771-780

[11]. Teng M, Wolf M, Lowrie E, Ofsthun N, Lazarus JM, Thadhani RI. Survival of patients undergoing hemodialysis with paricalcitol or calcitriol therapy. N Engl J Med. 2003;349(5):446-456.

[12]. Bodyak N, Ayus JC, Achinger S, et al. Activated vitamin D attenuates left ventricular abnormalities induced by dietary sodium in Dahl salt-sensitive animals. Proc Natl Acad Sci U S A. 2007;104(43):16810-16815

[13]. Bae S, Yalamarti B, Ke Q, et al. Preventing progression of cardiac hypertrophy and development of heart failure by paricalcitol therapy in rats. Cardiovasc Res. 2011;91(4):632-639.

[14]. National Kidney Foundation: KDOQI Clinical Practice Guidelines for Chronic Kidney Disease: Evaluation, classification, and stratification. Am J Kidney Dis 39:S1-S266, 2002 (suppl 1)

[15]. Go AS, Chertow GM, Fan D et al. Chronic Kidney Disease and the Risks of Death, Cardiovascular Events, and Hospitalization. N Engl J Med 2004; 351:1296-1305

[16]. Lang Roberto M., Badano Luigi P., Mor-Avi V et al; Recommendations for Cardiac Chamber Quantification by Echocardiography in Adults: An Update from the American Society of Echocardiography and the European Association of Cardiovascular Imaging. European Heart Journal - cardiovascular imaging. 16:3 2015:233-271.

[17]. Li S, Collins AJ. Association of hematocrit value with car- diovascular morbidity and mortality in incident hemodialysis patients. Kidney Int. 2004;65(2):626-633.

[18]. Glassock RJ, Pecoits-Filho R, Barberato SH. Left ventricular mass in chronic kidney disease and ESRD. Clin J Am Soc Nephrol. 2009;4(Suppl 1):S79-S91.

[19]. Wang A.Y., Fang F., Chan J., Wen Y.Y., Qing S., Chan I.H., Lo G., Lai K.N., Lo W.K., Lam C.W., et al. Effect of paricalcitol on left ventricular mass and function in CKD-The OPERA trial. J. Am. Soc. Nephrol. 2014;25:175-186. doi: 10.1681/ASN.2013010103.

[20]. Thadhani R, Appelbaum E, Pritchett Y, et al. Vitamin D therapy and cardiac structure and function in patients with chronic kidney disease: the PRIMO randomized controlled trial. JAMA. 2012;307:674-684.

[21]. Patange AR, Valentini RP, Gothe MP, Du W, Pettersen MD. Vitamin D deficiency is associated with increased left ventricular mass and diastolic dysfunction in children with chronic kidney disease. Pediatr Cardiol. 2013 Mar;34(3):536-42

[22]. Mukhopadyay $\mathrm{p}$, patar $\mathrm{k}$, chatarjee $\mathrm{n}$ and ganguly $\mathrm{k}$. Abnormal left ventricular mass index- a surrogate end point in vitamin $\mathrm{d}$ deficient chronic kidney disease. Nephrol. Dial. Transplant. (2014) 29 (suppl 3): iii114-iiil23.

[23]. Tove F, Ivy S, Per BG, Johan S, Johan A, Anders L, Håkan M, Lars L Ingelsson E. Relations of circulating vitamin D concentrations with left ventricular geometry and function. Eur J Heart Fail;Sep2012;14(9): p985

[24]. S. Pilz, R.M. Henry, M.B. Snijder, et al. Vitamin D deficiency and myocardial structure and function in older men and women: the Hoorn study. J Endocrinol Invest.2012(33):612-617

[25]. A.J. van Ballegooijen, M.B. Snijder, M. Visser, et al. Vitamin D in relation to myocardial structure and function after eight years of follow-up: the Hoorn study. Ann Nutr Metab.2012;60:69-77

[26]. Wang AYM, Lam CW et al. Serum 25-hydroxyvitamin D status and cardiovascular outcomes in chronic peritoneal dialysis patients: a 3-y prospective cohort study.Am J Clin Nutr.2008;87(6):1631-1638. 